\title{
Effect of tip vortices on flow over NACA4412 aerofoil with different aspect ratios
}

\author{
Mustafa Serdar Genç ${ }^{1, a}$, Gökhan Özkan ${ }^{1}$, Halil Hakan Açikel ${ }^{1}$, Mehmet Sadık Kiriş ${ }^{1}$, Rahime Yildiz ${ }^{1}$ \\ ${ }^{1}$ Wind Engineering and Aerodynamic Research Group, Department of Energy Systems Engineering, Erciyes University, Kayseri, Turkey
}

\begin{abstract}
Effect of tip vortices on flow and laminar separation bubble over NACA4412 aerofoil at low Reynolds numbers and different angles of attack was investigated in detail by performing force and flow visualization via smoke wire technique. Experiments have been done at Reynolds number of 50000 and the wing model of aspect-ratio was 1 and 3, respectively. From the experimental results, the flow visualization results showed that tip vortices effect on the laminar separation bubble and the bubble reduces over the wing with low aspect ratio as the angle of attack increased. Moreover, it was noticed that stall angles decreased as aspect-ratio increased at the same Reynolds number.
\end{abstract}

\section{Introduction}

The aerodynamic of low aspect-ratio wings have been extensively investigated by aerodynamic researches keen on low aspect ratio wings and low Reynolds numbers [119]. Viscous effects, separated and vortical flows are more prevalent and separation bubbles, transition, and reattachment processes are very attractive and also little understood at low Re number aerodynamics [1]. At low Reynolds number flow conditions, some negative effects are occurred such as decreasing on lift, increasing on drag, reducing stability of the aircraft, vibration, and noise due to the laminar separation bubble [4-11]. Genç et al. conducted an experimental [9] and numerical [11] studies over the NACA2415 aerofoil at various angles of attack and low Reynolds numbers. They noticed that due to the increasing Reynolds number and angle of attack the point of separation and reattachment moved towards to leading edge.

Recently, elliptical and rectangular wing model was thought to be hopefully for unmanned aerial vehicles (UAV), micro air vehicles (MAV) and other applications, since they were noticed that they could maximize the wing area for certain wing dimension. Thus, it can be said that is necessary to understand flow over the low aspectratio wings with these given wing models.

In these days, one study related to effects of aspectratio on the aerodynamic characteristics of wings at low Reynolds number has been presented by M. Mizoguchi and H. Itoh [12]. They firstly concluded that influences of aspect-ratio were not as important as they thought as aspect-ratio was 3 or more. But this situation was different at low aspect-ratios wings. Tip vortices had significantly important influences on aerodynamic characteristics of airfoil. Effect of tip vortices increased while aspect-ratio of wing decreased. Maximum lift coefficient and stall angle considerably increased as aspect-ratio was less or equal to 1. Okamoto and Azuma [13] investigated the effects of low Reynolds number and aspect ratios when Reynolds number was around 10000. Their results showed that stall angle increased significantly when aspect-ratio was less than or equal to 1. Torres and Mueller [14] studied low aspect-ratio wings and their characteristics at Reynolds number in the style of 100000 . Their studies showed same results for low aspect-ratio wings. Since, aspect ratio reduced to 1 and accordingly maximum lift coefficient and stall angles increased considerably. Other numerical experimental results [15-19] have demonstrated that low aspect-ratio wing performance is affected by both linear and nonlinear sources of lift.

In this report, the effect of the aspect ratio on the aerodynamic characteristics is investigated experimentally. After all tests, results are compared and discussed with literature studies if these experimental results are in coherence.

\section{Experimental Tests}

First of all, NACA4412 airfoil model was produced via $3 \mathrm{D}$ printer and then it was rubbed to obtain a smoother surface of wing as shown in Figure 1.

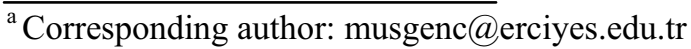




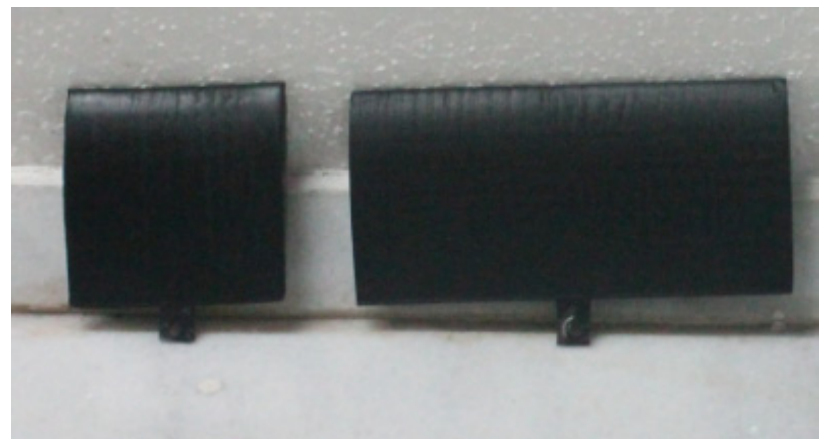

Figure 1. NACA4412 aerofoil model produced by 3D printer.

\subsection{Aerodynamic Force Coefficient for NACA4412 airfoil model}

In this study, NACA4412 airfoil model was produced with the aspect ratio of 1 and 3 were chosen at Reynolds number of 50000 and at the angles of attack from $0^{\circ}$ to $20^{\circ}$. Computer-controlled automatic angle changing force measurement system was used. Drag and lift forces were determined with strain-gauge which was connected to system. Then, these drag and lift forces were transformed into drag coefficient $\left(C_{D}\right)$ and lift coefficient $\left(C_{L}\right)$, respectively. Variations of drag and lift coefficients with angle of attack were given at Reynolds number of 50000 as shown in Figure 2.
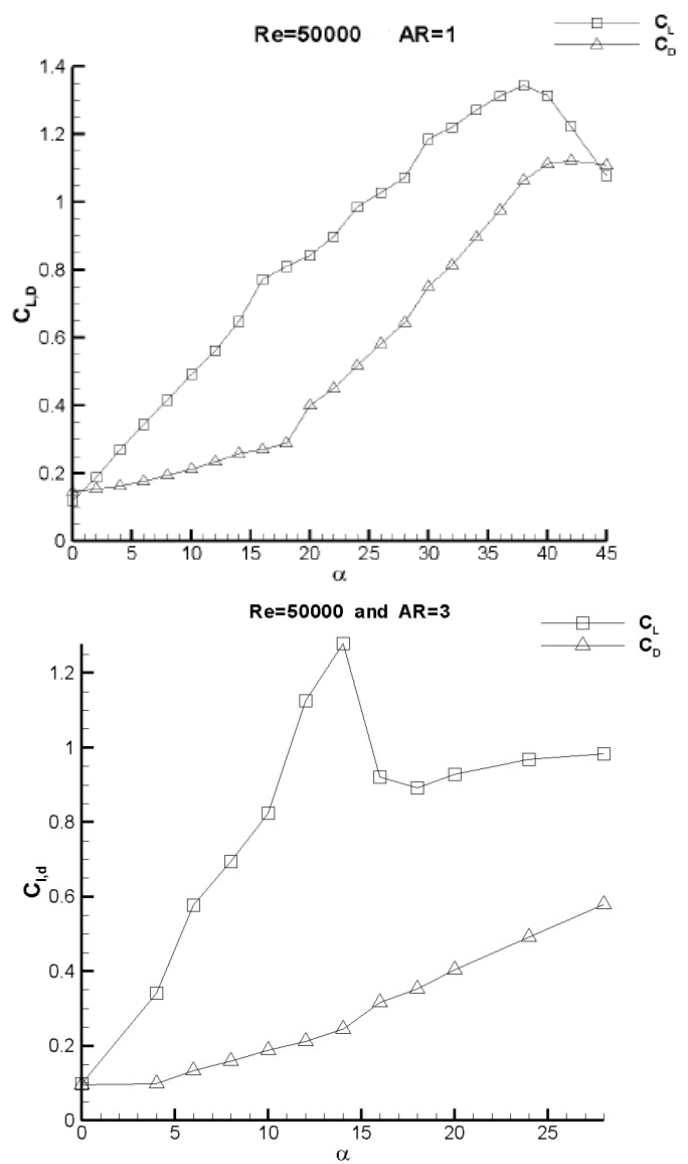

Figure 2. Aerodynamic force coefficient distributions for different aspect ratios at $\mathrm{Re}=50000$.
As seen from the figures, the stall angle is $38^{\circ}$ and $\mathrm{C}_{\mathrm{L}, \max }$ is 1.35 when the aspect-ratio is 1 . Yet, stall angle is $14^{\circ}$ and $\mathrm{C}_{\mathrm{L}, \max }$ is 1.25 as the aspect-ratio has been increased as 3 at same conditions. The cause of this situation is that the effects of tip vortices over the wing are seen more at low aspect ratio. Thus, stall angle at the aspect-ratio of 1 is bigger than value of $A R=3$. In addition to the results, it can be seen that stall at Reynolds number of 50000 for $\mathrm{AR}=3$ is sharper than stall for $\mathrm{AR}$ $=1$. That is, it can be said that abrupt stall is seen at aspect ratio of 3 whereas mild stall is seen at $\mathrm{AR}=1$.

\subsection{Flow Visualization Device}

The smoke-wire test for flow visualization technique is employed in this study. In smoke-wire flow visualization, different smoke-wire tests are applied for visualization with $\mathrm{AR}=1$ and $\mathrm{AR}=3$. As shown in Figure 3, $\mathrm{z} / \mathrm{c}$ was used as a term for location of smoke-wire. It can clearly be seen that this $\mathrm{z} / \mathrm{c}$ term is located of the outer portion of wing if it is negative sign.
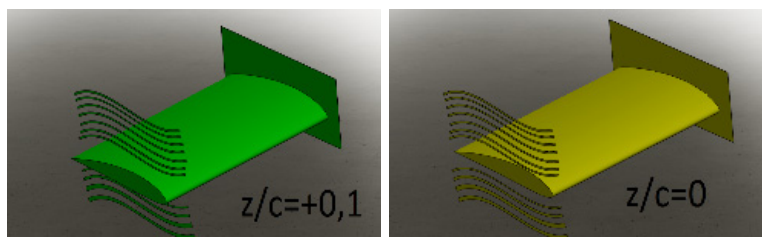

Figure 3. Different positions of smoke depending on the wire.

Flow visualization with smoke-wire test was presented for $\mathrm{AR}=1$ and $\mathrm{AR}=3$ at $\mathrm{Re}=50000$ as shown at Figure 4 and Figure 5. Moreover, flow visualization with smoke-wire test was also presented as top view of wing for $\mathrm{AR}=1$ and $\mathrm{AR}=3$ at $\mathrm{Re}=50000$ as shown in Figure 6 and Figure 7, respectively.

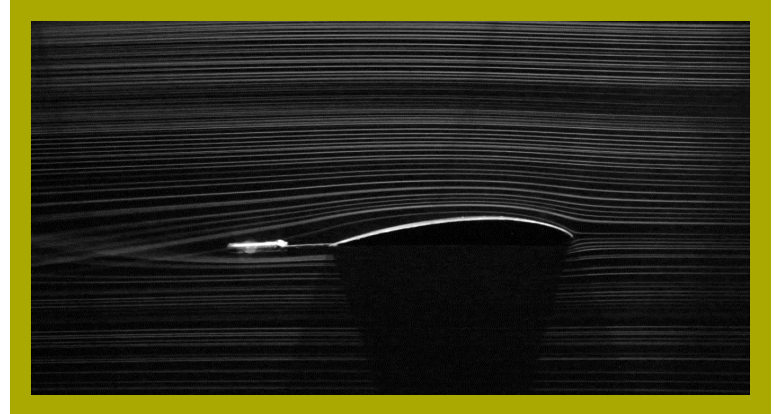

(a)

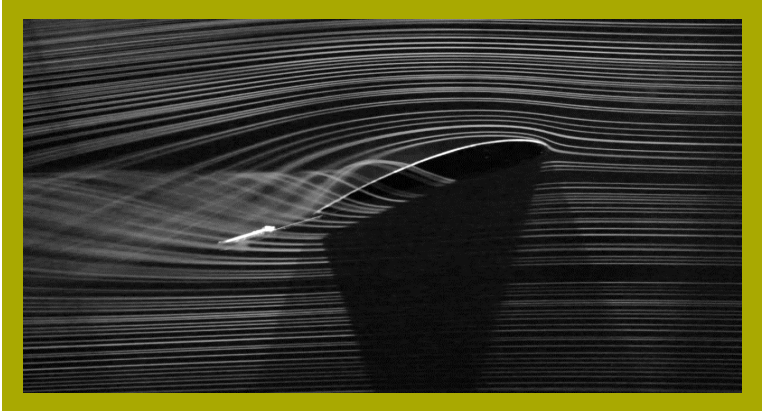

(b) 


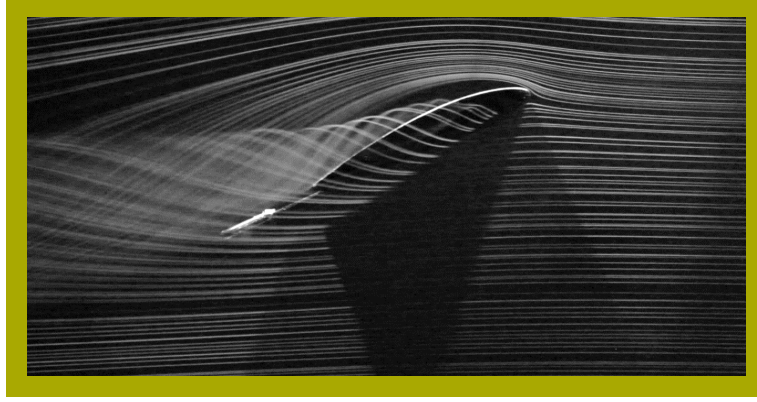

(c)

Figure 4. Flow visualization with smoke-wire test at Reynolds number of 50000 for $\mathrm{AR}=1$ and $\mathrm{z} / \mathrm{c}=0 \mathrm{a}) 0^{\circ}$, b) $16^{\circ}$, c) $24^{\circ}$.

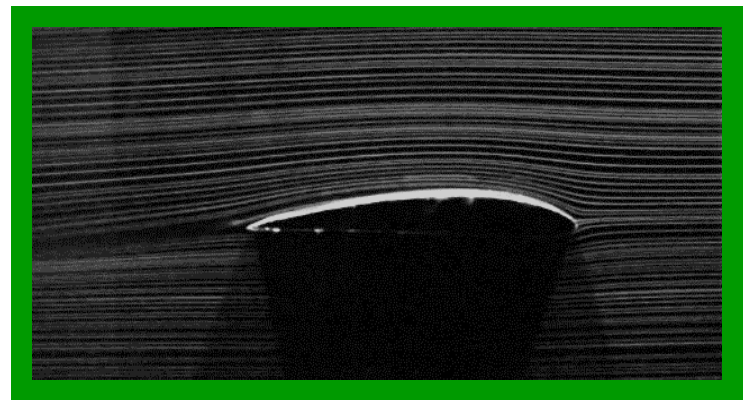

(a)

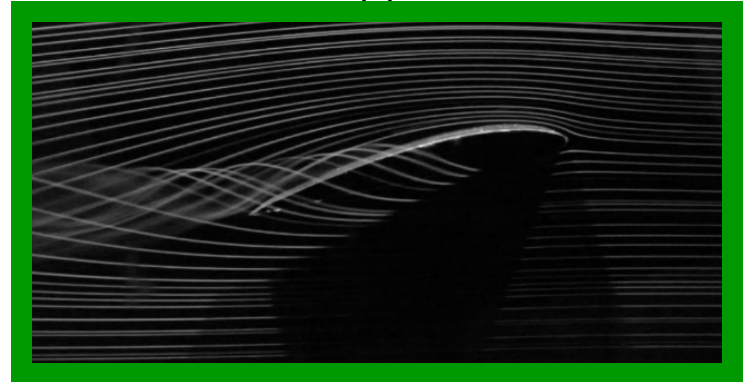

(b)

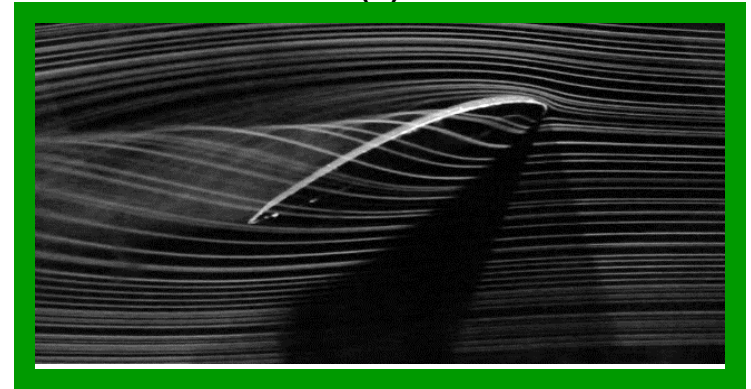

(c)

Figure 5. Flow visualization with smoke-wire test at Reynolds number of 50000 for $\mathrm{AR}=3$ and $\mathrm{z} / \mathrm{c}=+0.1$ a) $\left.0^{\circ}, \mathrm{b}\right) 16^{\circ}$, c) $24^{\circ}$.

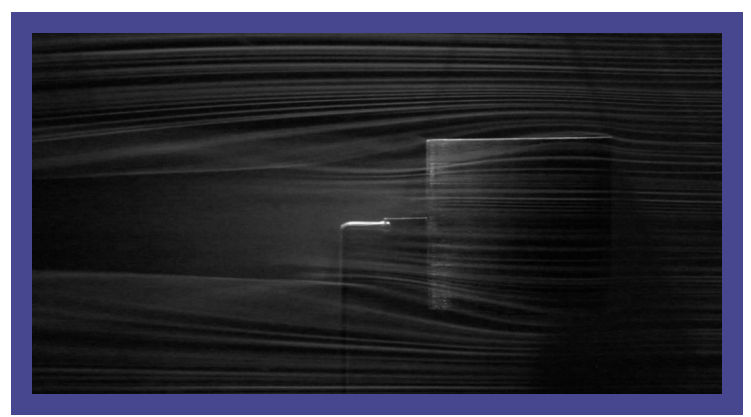

(a)

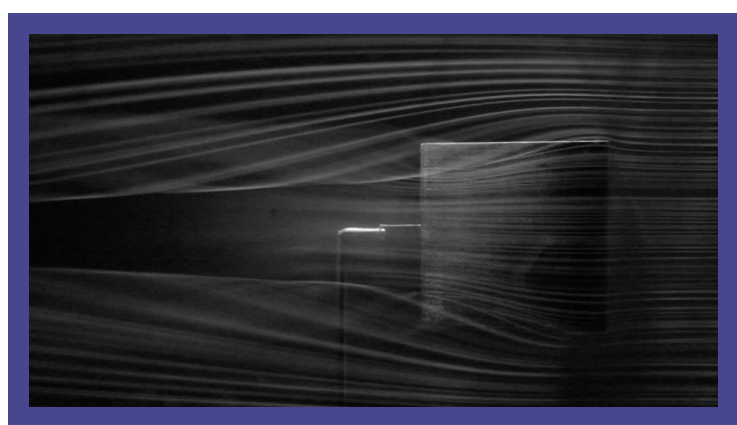

(b)

Figure 6. Flow visualization with smoke-wire test at Reynolds number of 50000 for $\mathrm{AR}=1$ and the top of view a) $4^{\circ}$, b) 16 .

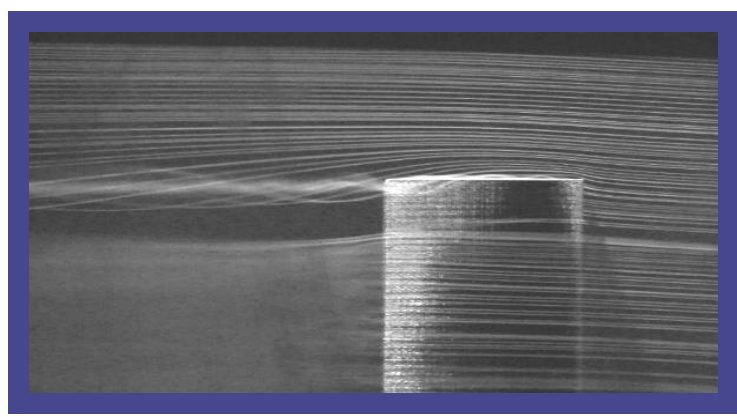

(a)

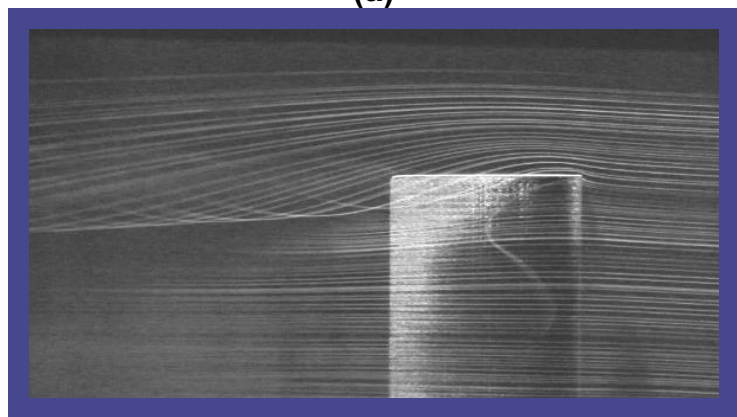

(b)

Figure 7. Flow visualization with smoke-wire test at Reynolds number of 50000 for $\mathrm{AR}=3$ and the top of view a) $4^{\circ}$, b) 16 .

In Figure (4a) and Figure (5a), flow over the wing model was in a normal way and was smooth. Tip-vortices became more dominant when angle of attack increased from $0^{\circ}$ to $24^{\circ}$. In this type of flow regions for $A R=1$ and $\mathrm{AR}=3$, laminar separation bubbles were affected by tipvortices. Tip-vortices over the wing model behaved like additional force which helped to attach for flow and separated flow at the middle of wing formed clinging flow at the tip of wing. Vortices coming from tips affected the majority of wing surface and instabilities increased. Also, rotational flow at wake region improved flows by doing vacuum effect with pressure drop.

For $\mathrm{AR}=1$, tip-vortices moved horizontally directed towards to middle of wing with increasing of angle of attack whereas they formed at the tip of wing at low angle of attack and continued to move towards to wake region of wing. Yet for $\mathrm{AR}=3$, movement of tip-vortices was limited as angle of attack increased. 


\section{Conclusion}

The aerodynamic characteristics and corresponding flow structures happened by separated shear layer and tipvortices over the wing upper surface at Reynolds number of 50000 for $\mathrm{AR}=1$ and $\mathrm{AR}=3$ have been experimentally investigated by using flow visualization technique like smoke-wire test and the force measurement tests. For low aspect-ratio wings, tipvortices have a considerable on characteristics of NACA4412 wing model. As mentioned earlier, value of maximum lift coefficient $\left(\mathrm{C}_{\mathrm{L}, \max }\right)$ is 1.35 and stall angle is $38^{\circ}$ for $\mathrm{AR}=1$ at Reynolds number of 50000 . On the other hand, $\mathrm{C}_{\mathrm{L}, \max }$ is 1.25 and stall angle $14^{\circ}$ when aspect-ratio has been increased from 1 to 3 . It can be noticed that the effect of tip-vortices increases when the aspect-ratio decreases. The results in regards to the sample of flow visualization with separation laminar shear layer, flow reattached property and generation of tip-vortices on the upper region of wing can be demonstrated by the corresponding flow structure showed at figures in the present report. This type of flow structures moves from tip of wing to middle of the wing when angle of attack increases. Yet, they will vanish and they will be replaced by huge portion of wake region after a while.

\section{Acknowledgments}

The authors would like to acknowledge funding from the Scientific and Technological Research Council of Turkey (TÜBITTAK) under the project no: 213M329.

\section{References}

1. I. Gursul, Vortex flows on UAVs: issues and challenges. Aeronautical Journal. 108(1090) 597-610 (2004)

2. M.S. Genç, Unsteady aerodynamics and flow-induced vibrations of a low aspect ratio rectangular membrane wing with excess length. Exp. Therm Fluid Sci. 44, 749759 (2013)

3. P. Rojratsirikul, M.S. Genc, Z. Wang, I. Gursul, Flowinduced vibrations of low aspect ratio rectangular membrane wings. J Fluid Struct. 27, 1296-1309 (2011)

4. R. Ricci, S.A. Montelpare, Quantitative IR thermographic method to study the laminar separation bubble phenomenon. Int $J$ Therm Sci. 44(8), 709-719 (2005)

5. W. Zhang, R. Hain, C.J. Kahler, Scanning PIV investigation of the laminar separation bubble on a SD7003 airfoil. Exp. Fluids. 45(4), 725-743 (2008)

6. M.S. Genc, U. Kaynak, G.D. Lock, Flow over an Aerofoil without and with Leading Edge Slat at a Transitional Reynolds Number. Proc IMechE, Part G: J Aerospace Eng. 223(3), 217-231 (2009)

7. M.S. Genc, Numerical Simulation of Flow over a Thin Aerofoil at High Re Number using a Transition Model. Proc IMechE, Part C-J Mech Eng Sci, 224(10), 2155 2164 (2010)
8. M.S. Genc, U. Kaynak, H. Yapıc1, Performance of transition model for predicting low $\mathrm{Re}$ aerofoil flows without/with single and simultaneous blowing and suction. Eur J Mech B-Fluid. 30(2), 218-235 (2011)

9. M.S. Genc, I. Karasu, H.H. Ac1kel, An experimental study on aerodynamics of NACA2415 aerofoil at low Re numbers. Exp Therm Fluid Sci. 39, 252-264 (2012)

10. M.S. Genc, I. Karasu, H.H. Acıkel, M.T. Akpolat, Low Reynolds number flows and transition, in: M. Serdar Genc (Ed.), Low Reynolds Number Aerodynamics and Transition, Intech-Sciyo Publishing, ISBN 979-953-307627-9 (2012)

11. I. Karasu, M. S. Genç, H. H. Açikel, Numerical study on low Reynolds number flows over an Aerofoil. J. Appl. Mech. Eng. 2, 131 (2013)

12. M. Mizoguchi, H. Itoh, Effect of aspect ratio on aerodynamic characteristics at low Reynolds numbers. AIAA Journal. 51(7), 1631-1639 (2013)

13. M. Okamoto, A. Azuma, Aerodynamic Characteristics at Low Reynolds Numbers for Wings of Various Planforms. AIAA Journal. 49(6), 1135-1150 (2011)

14. G. E. Torres, T. J. Mueller, Low Aspect-Ratio Wing Aerodynamics at Low Reynolds Numbers. AIAA Journal. 42(5), 865-873 (2004)

15. R. Bleischwitz, R. de Kat, B. Ganapathisubramani, Effects of aspect ratio on fluid-structure interactions in membrane wings. 52nd AIAA Aerospace Science and Technology Forum and Exposition, National Harbor, Maryland, (2014)

16. P.H. Cosyn, J. Vierendeels, Numerical Investigation of low aspect-ratio wings at low Reynolds Numbers. $J$. Aircraft. 43(3), 713-722 (2006)

17. S. Kaplan, A. Altman, M. O1. Wake vorticity measurements for low aspect-ratio wings at low Reynolds Numbers. J. Aircraft. 44 (1), 241-251 (2007)

18. E.V. Laitone, Wind tunnel tests of wings at Reynolds number below 70000. Exp. Fluids. 23(5), 405409 (1997)

19. M. Shields, K. Mohseni, Experimental complications inherent to low Reynolds number wind tunnel testing. AIAA Paper. 2011-0873. Orlando, FL. January 2011. 